Tanja MILOSHEVSKA

UDK: 316.774:343.326

Original research paper

\title{
CATEGORIZING THE RELATIONSHIP BETWEEN TERROSISM AND THE MEDIA
}

\begin{abstract}
This paper explains the delicate relationship between the media and terrorism in order to achieve a better understanding of the relationship between the two entities. In this paper, we will study both how publicity benefits terrorists, and how the media benefits from the acts of terrorists. The present paper will attempt to answer the following questions: How can we rethink the sensationalist coverage of terrorism and stop providing terrorists a free media platform? What kinds of relationships exist between terrorist groups and the media? To what degree can the media itself be held responsible for providing terrorism with the "oxygen of publicity"? Is it possible for the media to objectively report about terrorists without promoting their actions and instigating fear?

The purpose of this paper will be focused on the relationship between media coverage and terror attacks themselves, raising the question of whether increased coverage has an effect on the increased number of terrorist attacks.
\end{abstract}

Key words: MEDIA, TERRORISM, REPORTING, COMMUNICATION .

\section{Introduction}

This article examines the relationship between terrorism and the media. Terrorists use different types of media in a variety of ways, namely as an information instrument, to generate publicity and draw attention to their cause. It is argued that we cannot truly understand terrorism in the twenty-first century - let alone counter it effectively - unless we also understand the processes of communication that underpin it. Talking about communication - the sharing and transmitting of information - also means engaging with the role of the media. Over the past decade much has been said about the role of technologies like the Internet and the global communication networks in sustaining transnational terrorism, the spread of its ideology, and its recruiting activities.

Communication is important not only because terrorism is about transmitting a message or because terrorists might be disseminating their ideology through the Internet, but communication is also the very enabler of social interaction. Acknowledging the relevance of communication allows the understanding of how identities are formed, how people come to share a political cause and mobilise around it, as well as how political action can turn to violence. Besides, communication is not just relevant at ti- 
mes of terrorist attacks, but at all times. To really understand the role of communication, more or less mediated, in the phenomenon of terrorism we need to be able to see this broader picture. Thus, we need to ask ourselves if there is a symbiotic relationship between terrorism and the media.

\section{Reporting on different forms of terrorism}

The media (and the political spheres) tend to concentrate, depending on the period, on certain forms of terrorism. In the wake of an avalanche of attacks, references to Islam seem to pervade the media, as was seen following the attack in Munich in 2016 by a young German of Iranian origin. The mention of Iran misled news commentaries, with media once again focusing on Islam, whereas the crime was really committed because of an extreme right-wing ideology also rooted in the Aryan theories developed by certain Iranians and the culture of violence in Western societies, as the IranianAmerican journalist Alex Shams (2016) pointed out. In their studies and reports on terrorist risks, states and institutions take care not to limit themselves to religiously -inspired groups, and cover every threat. Thus, in its 2015 report, Europol also described extreme right-wing, anarchist and ethnonationalist organizations (EUROPOL, 2015).

The media selects events that are newsworthy (based on their own set of values that give priority to violence and conflict in any form). The broadcasting of a news program involves uncountable preparatory actions that involve the selection and discrimination of content that is daily placed on the desk of any entity that works and writes stories that will be published in the mass media. There is a competition between the different stories that will finally be emitted; those that are victorious are more dramatic, more spectacular in a visual sense, more emotional, and contain other elements that can be assimilated by an image-oriented culture.

The result is not only the shadowing of those events that, despite their interest, lack a conflicting nature, but the establishing of a dangerous pattern for those that want to be "made public" at any price (Ignatieff, 1998).

International media generally stress that these groups are engaged in a war against the West, but often fail to add that these violent actions often strike Muslim-dominant populations, either directly, as in Iraq and Syria, or indirectly, as was the case during the attacks in Brussels on 22 March 2016 and Nice on 14 July 2016, when there were also Muslims among the victims.

In fact, televised coverage of a terrorist attack's effects (especially if it is live) creates a paradoxical situation in which the spectators imagine more horrendous scenes than the ones that the very witnesses witnessed in the area (Ganor, 2005).

Therefore, what the media do in their narratives of reporting on terrorism, apart from their emphasis on the dramatic part of terrorist acts, is that they represent them by constructing a reality about terrorism or terrorists for us, and this representation or construction involves selection, exclusion and inclusion. In other words, the 
narrative in which terrorism is reported does not give it any legitimacy, and terrorists are denied a framing which takes into account the historical background and justness of their cause. "The terrorists are identified with criminal violence and seen simply as being bent on terror" (Schlesinger, et al, 1983).

The way a terrorist act is framed can also change over time. After a certain time-lapse, when the shock of the attack has faded, the media abandon the cohesional or patriotic frame they had established and entertain a greater diversity of views and opinions. After the Paris attacks in November 2015, Chris Elliott, the former readers' editor for The Guardian, remarked that "The idea that these horrific attacks have causes and that one of those causes may be the West's policies is something that in the immediate aftermath might inspire anger. Three days later, it's a point of view that should be heard" (Elliot, 2015).

The news media are owned and controlled by large corporations largely motivated by market share and profit. It is even more so today, now that terrorist groups have their own media such as Inspire (Al-Qaida) or Dabiq (Islamic State), technical teams, as well as social networks to disseminate their messages or stage their violent actions. Nowadays witnesses can publish a 'live stream' of attacks by using their smartphones and connecting to the main social networks, thus becoming "involuntary reporters", as Agence France-Presse has put it (Banet and Lemarchand, 2016). This affects their style, content, and reporting practices. Objective reporting is often outweighed by other factors, such as trying to acquire a larger share of the viewing market. The scoop and the exclusive news are prized objectives. Coverage can thus be selective, often allowing public opinion and government pronouncements to set the agenda for who the news will be spun. In such a political and market environment, the media will often miss criticism of counterterrorist policies.

\section{Deciding which incidents to report on and how to report}

Terrorism is a key testing ground, Charlie Beckett writes in Fanning the Flames. "Improving coverage of terrorism is important because violent extremism is a significant issue and symptomatic of wider problems around the world. The case for more intelligent, informed, and socially responsible reporting of terror is not just a moral plea, it is a chance to show that journalism remains a vital part of modern society" (Beckett, 2016).

The propensity of those in print and broadcast media has been to give priority to terrorist incidents in their news reports. This is understandable, given the influence, terrorism can have on policy making and either domestic or international political environments. However, the media have not been consistent about which incidents they report or how they report them. They frequently cover some acts of political violence extensively but provide little if any information about others (Rainey, 2005).

The result of the aforementioned situation is the existence of several corners of the planet that are never discussed in the news, despite the emergence of problema- 
tic situations that could affect the world as a whole. This asymmetric quality of the news causes terrorists to concentrate their efforts in those places where they can receive the media's attention, setting aside other places where their actions receive no interest aside from the violence itself (Soriano, 2008).

Furthermore, studies show that since suicide missions receive more media coverage as compared to other attacks due to the human sacrifice aspect, they are becoming increasingly popular amongst terrorist groups (Doward, 2015). This demonstrates the influence reporting has on terrorism. Finally, since western media is more developed and has a greater global presence, attacks in the western hemisphere are more prominent and more likely to occur (Daly, 2013). This is not to say that other parts of the world do not fall victims to terrorism; it simply places a target on high-profile cities such as Orlando, Paris, Istanbul and Moscow since a greater potential for outrage presents a greater opportunity to have a lasting impact on the society (Marthoz, 2017).

The process for deciding which events to report is often driven by the evaluation of what kind of news are likely to attract an audience. If it is decided that dramatic incidents will bring in sizable shares of viewers, the media will not hesitate to prioritize such incidents for the day's editions or broadcast. The media can be highly selective about which terrorist incidents to report on. The ultimate decision tends to weigh in favor of what most affects readers or the viewing public.

The frame is expressed through the selection or rejection of subjects, their hierarchy, their placement, the choice of speakers and images. It can also be reflected in the use of some words and epithets. By comparing two attacks, one in Beirut on 12 November 2015, the other in Paris on 13 November 2015, the Lebanese-American journalist Nadine Ajaka showed how a few words were enough to set up a frame that can influence the public's feelings. News agencies described the attacks in Beirut as an attack against "a stronghold of Hezbollah, the Shiite militant group". By enveloping the area in a communitarian and geopolitical commentary and thus compacting its diverse identities, these news agencies implied, to a certain extent, that the crime was only to be expected as the Lebanese Shiite militia is an enemy of the Islamic State. There was no such characterisation in the coverage of the Paris attacks, and the media only marginally referred to France's military interventions against the Islamic State group (Ajaka, 2015).

Deciding how to report on terrorist incidents is, from the reader or viewer's perspective, seemingly a subjective exercise. Media reports have never been consistent in their description of the perpetrators of terrorist incidents, nor have they been consistent in characterizing examples of extremist violence as terrorism per se (Gus, 2011).

The outcome of reporting on terrorism links to the symbiotic, or mutually-beneficial, relationship between terrorist groups and the media (Bilgen, 2012). Given the nature of modern mass media, outlets and journalists alike are constantly on the hunt for the next big story, falling right into the terrorists' plan. In their quest for attentiongrabbing headlines and rapid-fire reporting, outlets can often be seen going head to head for information and over-reporting on a given incident. To demonstrate this, one 
can compare coverage of an act of terrorism, such as the March 22nd Westminster attack, with an equally devastating occurrence such as Hurricane Matthew, which made its way to southeastern US in October 2016. Though Hurricane Matthew had a greater number of casualties (an estimated six-hundred to four from March), there was minimal coverage beyond the initial reporting. The Westminster attack, however, was in the international press for weeks. From the initial reporting, to follow-ups with government officials, and finally broadcasting of victim interviews, the terrorist's reach was amplified due to the number of articles devoted to the attack and thus their message travelled a greater distance (Rivera, 2016).

\section{Terrorism and the media: a misunderstood relationship}

While there appears to be an agreement about the existence of a relationship between media and terrorism, the literature at closer scrutiny reveals a range of different and conflicting claims. Paletz and Boiney $(1992,10)$, for example, point out that "there are two diametrically opposed camps: those that indict the media as pro-terrorist and those that indict the media as antiterrorist." The "very few works" belonging to the latter camp accuse the media of conspiring with the corporate and/or political power to support a narrow understanding of terrorism, one that is instrumental to pursuing specific interests. (Paletz and Boiney, 12-13). Kevin Barnhurst (1991 115-119) also identifies "two schools": one which sees the media as "culpable," and instrumental to terrorism; another one arguing that the media are "vulnerable," victims themselves of manipulation by terrorists, yet not directly responsible for terrorists' deeds. Despite this variety of views, the overall understanding of the media role in relation to terrorism in the literature appears overwhelmingly negative.

The dependence of terrorists on the media to publicise their message -one of the most recurrent quotes is by Walter Laqueur $(1976,104)$ : "The media are the terrorist's best friend. The terrorist's act alone is nothing: publicity is all" - has led to establishing, more or less explicitly, a causal link between terrorism and media coverage. Jenkins in (Eke and Alali, 8) goes so far as to say that "terrorism is a product of freedom, particularly, of the freedom of the press." For Nacos $(1994,8)$ : "Getting the attention of the mass media, the public, and decision makers is the raison d'etre behind modern terrorism's increasing shocking violence."

The relationship between media and terrorists is often described as a "symbiosis" (Wilkinson, 145). On the one hand, terrorists need to publicise their motives through the media; on the other hand, media outlets constantly seek compelling stories for their audiences. On this aspect, in her study on the causes of terrorism, Martha Crenshaw $(1981,386)$ writes: "The most basic reason for terrorism is to gain recognition or attention... Violence and bloodshed have always excited human curiosity, and theatricality, suspense, and threat of danger inherent in terrorism enhance its attention-getting qualities." 
The role of the media within the symbiotic relationship with terrorism can vary, however. While the media are always somehow linked to the idea that they support terrorism, the ways in which they can actually aid terrorists in advancing a cause can take different forms.

Media can encourage terrorism through "contagion" (Bassiouni, 19): the idea is that the media attention towards terror will encourage further incidents by providing a "model and inspiration" for more attacks (Schmid, 558).

The majority of a considerable amount of academic literature where this topic has been discussed has pointed out the symbiotic relationship between terrorism and the mass media. Abraham Miller talks about the symbiotic relationship between terrorism and media, from which neither of the two can step out. He noted: "terrorism is capable of writing any drama - no matter how horrible - to compel the media's attention ... Terrorism, like an ill-mannered enfant terrible, is the media's stepchild, a stepchild whom the media, unfortunately, can neither completely ignore nor deny" (Tuman,115).

Barnhurst proposes two models that try to describe the relationship between terrorism and the media.

The first model is the culpable-media model. According to this model, the media complete a vicious circle. By reporting on terrorist attacks, the media play a part in conveying terrorist messages to a large audience. This is a key aim for terrorist organizations, and therefore encourages them to carry out more attacks, which will in turn be reported by the media. This creates a vicious circle, in which terrorist carry out attacks, which are reported by the media, and which subsequently lead to more attacks. In a sense, the model identifies the media as a cause for terrorist attacks.

The second model is called the vulnerable media model, and views the media as a victim of terrorism rather than a cause. In this notion, it is proposed that, even though the media could theoretically stop covering terrorism, this would not be enough to end terrorist activities. Terrorists do not have to rely on any media outlet for their communication. This is because of the existing competition in the current media system (Barnhurst, 1991). In addition, a "breaking news mentality" is deeply rooted in the media. This means that every newspaper, television network, or radio station constantly tries to be the first to cover a news item, which enables them to draw large audiences to their particular news feed (Glüpker, 2008). This is caused by the increasing competition among media to cover news items as quickly as possible (Kushner, 2000). In some cases, this pressure can cause journalists to underestimate the consequences of reporting on terrorism, or lead to incorrect interpretations of the activities of terrorist organizations.

The diversity of causes, ideologies, and social and cultural conditioning factors that inspire different terrorist groups are equally applicable to the type of relationships that these groups establish with the news media. Four different models of behaviour exist: 
1. Complete indifference. The terrorists' goal is to terrorize their victims, without seeking to attain media attention for their acts. There is no expectation that the press will become involved (this situation is highly unusual).

2. Relative indifference. The terrorists are not concerned with being on the news, even though they are conscious of the power that explaining their cause in currently existing media can provide them.

3. A media-oriented strategy. The terrorists are not only aware that the press can expand the scope of their words and actions, but they also perform a series of operations based on the knowledge that they possess on the dynamics and functioning of the news producers. After well-thought-out manipulations, the news media becomes integrated in the terrorist group's actions. (The 7/7 bombings in London that resulted in an avalanche of reports on the sentiments and grievances of Muslims in the United Kingdom and elsewhere in Europe and on the role of the Iraq war in the recruitment of home-grown British subjects. The U.S. news media did carry stories on the radicalization of young Muslims in the European Diaspora before 7/7, but this coverage paled in comparison to far more in-depth reporting on the predicament of Muslims in Western Europe. Once again, horrific acts of terrorism triggered news coverage that informed the public in the United Kingdom and all over the globe about situations and developments that should have been part of news reports all along).

4. Complete breakaway. This is the case of terrorists that see journalists and reporters as enemies that must be destroyed, putting them on the same level as other direct adversaries. The press ceases to be an entity that should be cynically manipulated (as democracy's Achilles' heel). It is instead viewed as the appendix of a system that must be destroyed (Wieviorka, 2004). (American journalist James Foley was executed by terrorist organizations ISIS on August 20, 2014).

These four options do not only give us an idea of the variety of possible relationships that can be established between these two entities, but they also allows us to see how terrorists can alternate between different models, or even adopt more than one at the same time. In fact, modern terrorist groups frequently employ strategies that work to satisfy the news media's demands, while at the same time considering them an integral part of an enemy that they seek to overcome and annihilate.

In the end, we must take definitive steps to ensure that the media doesn't increase the likelihood of another terrorist attack. Otherwise, we will live in a horrible reality where every article we write on terrorism may very well provide a stepping-stone for the next attack. 


\section{Conclusion}

The media (and political spheres) tend to concentrate, depending on the period, on certain forms of terrorism. From about 1960 to 1980, the news mainly covered terrorism linked to the extreme right and left and pro-independence movements. While such terrorism has not completely disappeared, today, "religiously-inspired terrorism" attracts the most attention, and particularly attacks instigated by organizations claiming to follow Islam, which generate the widest media coverage.

Access to the media brings terrorists closer to a democratic society's decisionmaking process, which significantly increases chances that this complex network of interactions will end with a result in a political decision that favours the interests of their group. The press also has its own incentives to report major terrorist incidents. From the media points of view and aside from its fundamental responsibility to objectively report the news-drama guarantees increased attention from viewers.

In other words, it is the type of relationship between two groups involving mutual dependence where one party complements the other. There is, however, more than one type of relationship that can exist between terrorists and the mass media. The diversity of causes, ideologies, and social and cultural conditioning factors that inspire different terrorist groups are equally applicable to the type of relationships that these groups establish with the news media. 


\section{References}

Ajaka, N. (2015). Paris, Beirut, and the Language Used to Describe Terrorism. The Atlantic. Available at: http://www.theatlantic.com/international/archive/2015/11/pa ris-beirut-media-cover-age/416457/ [Accessed 25 Jan. 2018].

Barnhurst, K. G. (1991). "The Literature of Terrorism: Implications for Visual Communications." in A. O. Alali and K. K. Eke (Eds). Media Coverage of Terrorism: Methods of Diffusion. London: Sage.

Bassiouni, M. C. (1981). "Terrorism, Law Enforcement, and the Mass Media: Perspectives, Problems, Proposals'." Journal of Criminal Law and Criminolog, 72 (1).

Beckett, C. (2016). Fanning the Flames: Reporting on Terror in a Networked World, TOW Reports. Tow Center for Digital Journalism at Columbia's Graduate School of Journalism, USA.

Bilgen, A. (2012). "Terrorism and the Media: A Dangerous Symbiosis." International Relations, Jul 22.

Corey, S. (2015). "The Aftermath of the Paris Attacks Is a Time to Grieve, Not Fear Monger." Huffington Post, 11/14.

Crenshaw, M. (1981). "The Causes of Terrorism." Comparative Politics 13 (4).

Daly, K. (2013). "Media Oriented Terrorism: The Role of Media in Influencing Terrorist Attacks and the Shaping of Public Opinion.". Available at: https://www.academia.edu/7619826/Media_Oriented_Terrorism_The_Role_of_Media_in_Influenci ng_Terrorist_Attacks_and_the_Shaping_of_Public_Opinion.

Doward, J. (2015). "Media coverage of terrorism 'leads to further violence'." The Observer. Guardian News and Media.

Eke, K. K., A. O. Alali (1991). "Introduction: Critical Issues in Media Coverage of Terrorism." in A. O. Alali and K. K. Eke (eds). Media Coverage of Terrorism: Methods of Diffusion. London: Sage.

Elliot, C (2015). What we got right and wrong in coverage of the Paris attacks. Guardian. Available at: https://www.theguardian.com/commentisfree/2015/nov/23/whatwe-got-right-and-wrong-in-coverage-of-the-paris-attacks [Accessed 25 Jan. 2018].

EUROPOL (2015). Available at: https://www.europol.europa.eu/content/european-union -terrorism-situation-and-trendreport-2015. [Accessed 20 Jan. 2018].

Ganor, B. (2005). The Counter-Terrorism Puzzle. A Guide for Decision Makers. New Brunswick, USA: Transaction Publishers.

Glüpker, G. (2008). Media and terrorism. Norderstedt: Germany.

Gus, M. (2011). Essentials of terrorism: concepts and controversies. California: Sage Publications, Inc, USA.

Ignatieff, M. (1998). Warrior's Honour: Ethnic War and the Modern Conscience. New York: Henry Holt and Co. 
Kushner, H.W. (2000). The Impact of terrorist events in the media on the traumatisation of society. United Nations Center. Vienna. Austria, April 12.

Laqueur, W. (1976). “The Futility of Terrorism.” Harper's Magazine, 252(1510): 99-105.

Marthoz, J. P. (2017). "Terrorism and the Media." UNESDoc. UNESCO.

Nacos, B. L. (1994). Terrorism and the Media: From the Iran Hostage Crisis to the Oklahoma City Bombing. New York: Columbia University Press.

Paletz, D. L., Boiney, J. (1992). “Researchers' Perspectives.” in D. L. Paletz and A. Schmid (eds). Terrorism and the Media: How Researchers, Terrorists, Government, Press, Public, Victims View and Use the Media. London: Sage.

Rainey, J. (2005). 'Unseen Pictures, Untold Stories'. Los Angeles Times, May 21.

Rémi Banet, R., Lemarchand, G. (2016). Involuntary reporters. AFP Correspondent. Available at: https://correspondent.afp.com/involuntary-reporters. [Accessed 20 Jan. 2018].

Rivera, J. D. (2016). "The Symbiotic Relationship between Western Media and Terrorism." Carnegie Council for Ethics in International Affairs, May 24.

Schlesinger, P, et al. (1983). Televising Terrorism: Political Violence in Popular Culture. London: Comedia Publishing Company.

Schmid, A. P. (1989). "Terrorism and the Media: The Ethics of Publicity." Terrorism and Political Violence, 1 (4).

Shams, A. (2016). Why Did The Munich Killer Beg Us To See Him As German? The Blog. Available at: http://www.huffingtonpost.com/alex-shams/why-did-themunich-killer_b_11154486.html. [Accessed 15 Dec. 2017].

Soriano, T. (2008). Terrorism and the Mass Media after Al Qaeda: A Change of Course? Athena Intelligence Journal, Vol. 3, No 1.

Tuman, J.S. (2003). Communicating Terror: The Rhetorical Dimensions of Terrorism. London: SAGE Publications.

Wieviorka, M. (2004). The making of Terrorism. Chicago: The University of Chicago Press.

Wilkinson, P. (2006). Terrorism Versus Democracy: The Liberal State Response. 2nd edn, New York: Routledge. 